\title{
Time dependent density functional study of the absorption and emission spectra of 1,3-benzoxazole and three substituted benzoxazoles
}

\section{Estudio teórico de los espectros de absorción y emisión de la 1,3- benzoxazol y tres de sus derivados desde la perspectiva de la teoría de los funcionales de la densidad}

\author{
R. J. Carrasquilla ${ }^{*}$ y O. L. Neira \\ Departamento de Física, Grupo de Espectroscopia Óptica y Láser, Universidad Popular del Cesar, Valledupar, \\ Colombia. \\ (") Email: rjcarrasquilla@yahoo.com \\ Recibido / Received: 15/05/2012. Revisado / Revised: 24/07/2012. Aceptado / Accepted: 25/07/2012. \\ DOI: http://dx.doi.org/10.7149/OPA.45.3.287
}

\begin{abstract}
:
Time dependent density functional Theory (TD-DFT) calculations were performed on 1,3benzoxazole and three substituted benzoxazoles using the B3LYP functional and the $6-31+G(d)$ base set. The geometry of the $S_{0}$ and $S_{1}$ singlet ground and excited states were optimized in the gas phase, toluene and methanol, and the vertical $\left(\pi \rightarrow \pi^{*}\right)$ absorption and emission largest wavelength transitions were determined. Tree benzoxazoles substituted were studied and good agreement with experiment was found in all cases.
\end{abstract}

Key words: Absorption and Emission Spectra, TD-DFT Methods, Benzoxazole.

\section{RESUMEN:}

En este trabajo se realizó un estudio teórico de los espectros de absorción y emisión de cuatro miembros de la familia de los benzoxazoles desde la perspectiva de la teoría de los funcionales de la densidad en su versión dependiente del tiempo (TD-DFT), empleando la funcional híbrida B3LYP y el conjunto de funciones base $6-31+\mathrm{G}(\mathrm{d})$. Las geometrías del estado fundamental $\left(\mathrm{S}_{0}\right)$ y del primer estado singlete excitado $\left(S_{1}\right)$ fueron optimizadas en fase gas y en fase líquida (metanol y tolueno). Finalmente, se determinó las transiciones verticales $\left(\pi \rightarrow \pi^{*}\right)$ que dan origen a los espectros de absorción y emisión de cada una de las estructuras estudiadas obteniendo resultados acordes con los datos experimentales.

Palabras clave: Espectros de Absorción y Emisión, Métodos TD-DFT, Benzoxazol.

\section{REFERENCIAS Y ENLACES / REFERENCES AND LINKS}

[1]. V. V. Gruzinzkiy, Research on the Effectiveness of Energy Conversion from Electrical and Optical Excitation of Complex Molecules Free, PhD Thesis in Physics and Mathematics, Minsk (1982).

[2]. U. J. Kim, Propiedades Luminiscentes y de Generación láser y Fotoestabilidad de los Naftaliminidos, PhD Thesis in Optics and Laser Physics, Minsk (1989).

[3]. S. J. Bai, C. C. Wu, T. D. Dang, F. E. Arnold, B. Sakaran, "Tunable and white light-emitting diodes of monolayer fluorinated benzoxazole graft copolymers", Appl. Phys. Lett. 84, 1656-1658 (2004).

[4]. T. M. H. Costa, S. Valter, M. R. Gallas, N. M. Balzaretti, J. A. H.da Jornada, "Fluorescence properties of benzoxazole type dyes entrapped in a silica matrix by the sol-gel method", J. Nucl. Med. 48, 33773381 (2001). 
[5]. Y. H. So; J. M. Zaleski, C. Murlick, A. Ellaboudy, "Synthesis and photophysical properties of some benzoxazole and benzothiazole compounds", Macromolecules 29, 2783 -2795 (1996).

[6]. V. V. Gruzinskii, T. G. Staneva, "Spectral-luminiscent properties that determine the generation capacities and features of phthalimides", J. Appl. Spectrosc. 29, 614-620 (1978).

[7]. O. K. Bazyl', G. V. Maier, T. N. Kopylova, V. I. Danilova, V. K. Chaikovskii, "A theorethical and experimental investigation of the laser action of phenylethynyl-substituted dyes", J. Appl. Spectrosc. 35, 261-267 (1981).

[8]. S. M. Alexandrovich, Investigación de las Propiedades Espectro-luminiscentes del Estilbeno y sus Derivados, PhD Thesis in Optocs and Laser Physics, Minsk (1982).

[9]. R. J. Carrasquilla, O. L. Neira, "Time dependent density functional study of the absorption spectra of 1,3-benzoxazole and three substituted benzoxazole in gas phase and liquid phase", J. Phys.: Conf. Ser. 274 (2011).

[10]. Gaussian 09, Revision A.01, M. J. Frisch, G. W. Trucks, H. B. Schlegel, G. E. Scuseria, M. A. Robb, J. R. Cheeseman, G. Scalmani, V. Barone, B. Mennucci, G. A. Petersson, H. Nakatsuji, M. Caricato, X. Li, H. P. Hratchian, A. F. Izmaylov, J. Bloino, G. Zheng, J. L. Sonnenberg, M. Hada, M. Ehara, K. Toyota, R. Fukuda, J. Hasegawa, M. Ishida, T. Nakajima, Y. Honda, O. Kitao, H. Nakai, T. Vreven, J. A. Montgomery, Jr., J. E. Peralta, F. Ogliaro, M. Bearpark, J. J. Heyd, E. Brothers, K. N. Kudin, V. N. Staroverov, R. Kobayashi, J. Normand, K. Raghavachari, A. Rendell, J. C. Burant, S. S. Iyengar, J. Tomasi, M. Cossi, N. Rega, J. M. Millam, M. Klene, J. E. Knox, J. B. Cross, V. Bakken, C. Adamo, J. Jaramillo, R. Gomperts, R. E. Stratmann, O. Yazyev, A. J. Austin, R. Cammi, C. Pomelli, J. W. Ochterski, R. L. Martin, K. Morokuma, V. G. Zakrzewski, G. A. Voth, P. Salvador, J. J. Dannenberg, S. Dapprich, A. D. Daniels, O. Farkas, J. B. Foresman, J. V. Ortiz, J. Cioslowski, D. J. Fox, Gaussian Inc., Wallingford CT (2009).

[11]. M. Cossi, V. Barone, "Time-dependent density functional theory for molecules in liquid solutions", J. Chem. Phys. 115, 4708-4717 (2001).

[12].N. M. O'Boyle, A. L. Tenderholt, K. M. Langner, "Cclib: A library for package-independent computational chemistry algorithms", J. Comput. Chem. 29, 839-845 (2008).

[13]. R. Passerini, "The near-ultra-violet absorption spectra of some heterocyclic compounds", J. Chem. Soc. 1, 2256-2261 (1954)

[14].I. S. Irgibaeva; D. A. Birimzhanova; N. N. Barashkov, "Research of electronic absorption spectra of benzazols derivatives by ab initio calculations", Int. J. Quantum Chem. 108, 2700-2710 (2008).

\section{Introduction}

The family of benzoxazole (1,3-benzoxazole and derivatives) constitute one of the main groups of organic fluorescent materials. They have been studied for their interesting photo-physical and spectroscopic properties. This class of organic compounds shows the fluorescence emission with a large Stokes shift due to intramolecular protonic transfer that has reaction on the excited electronic state. A phenomenon that has important applications for the functioning of many dyes lasers, like photo sensitizers, as well as research in physics, chemistry, technology applications and their use in medicine and biology. From the point of view of its optical properties (absorption, emission and quantum yield), the benzoxazole derivatives have been much studied as components of organic dye laser systems where our main interest in these compounds lies, and fluorescent probes. In this form we make a contribution to the solution of the common problem for both the spectroscopy and physics of the laser, known as: "The first fundamental problem of common interest for Optical Spectroscopy and Laser Physics", which is related with the search of active medium for tunable lasers based on dyes, thereby seeking the greatest coverage of the spectral band with the laser effect $[1,2]$.

Once you try to find a solution to this problem, in the proposals reported in the literature is the use of three-ring compounds and more complex structures that contain such fragments. Among those structures are included some derivatives of the benzoxazole, since has been experimentally demonstrated in some of these best properties of absorption, fluorescence and laser effect $[3,4]$. On the other hand, we know that the proper alteration of a molecular structure initial (parent structure), in many 
cases has allowed to obtain the laser effect in other regions of interest of optical spectral. All this shows how it is possible to go covering different spectral regions and expand more and more spectral coverage with the laser effect using dyes as active medium [8].

All in all, in this paper it reports a theoretical study of the absorption and emission spectra of four member's families of benzoxazole (parent structure and three derivative structures). Theoretical study for the 1,3-benzoxazole (parent structure) already been reported by the same author, but to ground state and absorption spectra only [9]. In this paper we extend the study to some substituted benzoxazole, not yet included in previous works, in order to obtain conclusions about the effect of substituent in the red shift of the fluorescence bands of the parent structure.

\section{Methodology and computational details}

Quantum chemical calculations were carried out using the Gaussian 09 program [10] package. Calculations were performed mainly in four steps. Geometry optimization of the molecules in the ground state was performed at the B3LYP/6$31+G(d)$ level. These calculations were followed by a determination of the Hessian to assess whether the stationary points obtained were minima and to obtain the vibrational spectrum of each structure. The second step consisted in a TD-DFT calculation of the absorption spectrum of the molecules. Normally up to 10 singlet excited states were included in the calculations but only the one or two lowest states were included in the discussion. The third step consisted in the geometry optimization of the chosen excited state, normally obtaining a

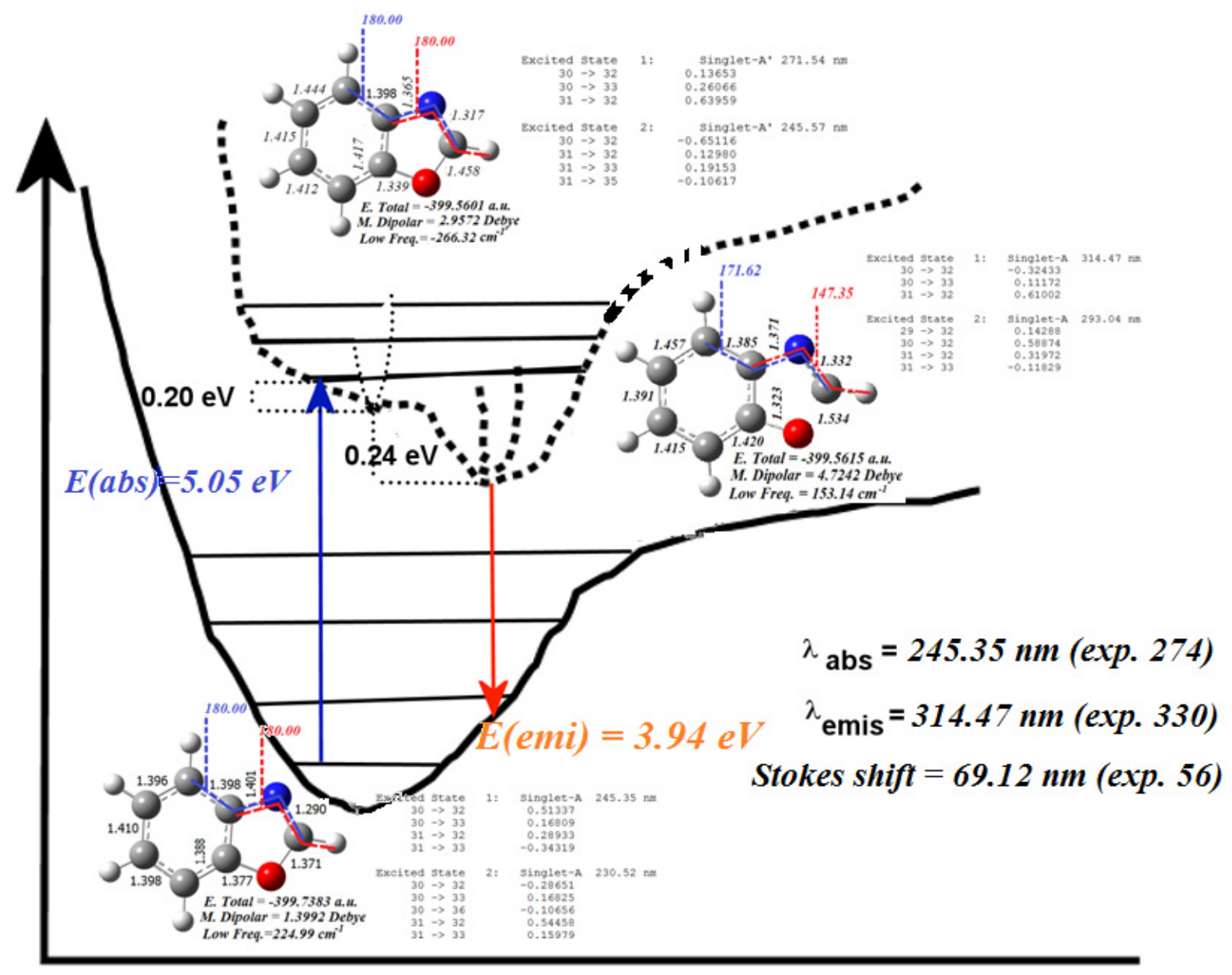

Fig. 1: Scheme from process methodological to obtain the absorption and emission spectra for the 1,3-benzoxazole. 
transition state. Starting from this structure one seeks along the transition vector to find the minimum that we permit the evaluation of the emission spectrum. The image in Fig. 1 shows the schematic process for the parent structure.

The solvent effect was simulated by a polarizable continuum model (PCM). Inclusion of the solvent is crucial for the prediction of optical properties comparable to the experiments in the case of dye lasers, since the organic dye is most frequently dissolved in an organic solvent. Both equilibrium and non-equilibrium solvation were considered. The first calculations are actually more appropriate for phenomena long enough to allow the reaccomodation of the solvent (phosphorescence, for instance) while nonequilibrium solvation is more appropriate for fast processes like fluorescence [11]. We performed both calculations to assess the difference to be expected due to the solvent reorganization effect and found no significant differences. The solvents used in our calculations were ethanol (dipole moment: 1.84 Debye and dielectric constant: 24.8) and toluene (dipole moment: 0.36 Debye and dielectric constant: 2.4). So that, the ethanol is considerate a polar solvent while the toluene, a nonpolar solvent. The UV-Vis spectra were plotted using the GausSum 2.2 Ob computer program [12].

The structures studied are depicted in Table I. Besides the parent molecule (structure I), three phenyl substituted artificial benzoxazoles were studied: The 2-phenyl-1,3-benzoxazole (structure II), is included to study the effect of lengthening the chain of pi-conjugated bonds, while 2-orto-fluorine-phenyl-1,3-benzoxazole (structure III) and 2-(2-hydroxyphenyl)-1,3benzoxazole (structure IV) are included in order to obtain conclusions about the effect of substituent in the red shift of the fluorescence bands of the structure II.

\section{Results and discussion}

\section{3.a. Geometries and charges of the ground states}

The optimum geometrical structure each molecule studied of the ground state in the gas phase is shown in Fig. 2 and the serial numbers of atoms are also indicated. The variations suffered from the geometrical parameters due solvent effect (ethanol and toluene are used), are shown in Table II, the difference obtained for bond lengths are mostly below a few thousandths of an $\AA$, but in the direction that was expected because of the electrostatic stabilization of the dipole moment. The charges calculated (by Mulliken) at each structure are shown in Table III. One can see that the inclusion of the ethanol polarizes the charges in the expected direction for a polar solvent, increasing the charge transfer from the benzene fragment to the oxazole ring. The same effect is observed in the dipole moment, which increase once increases the dielectric constant of the solvent, see last row of the Table III. Each structure is a minimum, as shown by the positive lowest eigenvalue of the Hessian, see Fig. 2.

The ground state of the parent structure exhibits an almost completely planar configuration with alternating, delocalized $\pi$ bonding on benzene ring, the $\mathrm{O}-\mathrm{C}$ bonds are almost equal and there is a clear $\mathrm{C}-\mathrm{N}=\mathrm{C}$ alternating single and double bond configuration

Table I

Molecular structures.

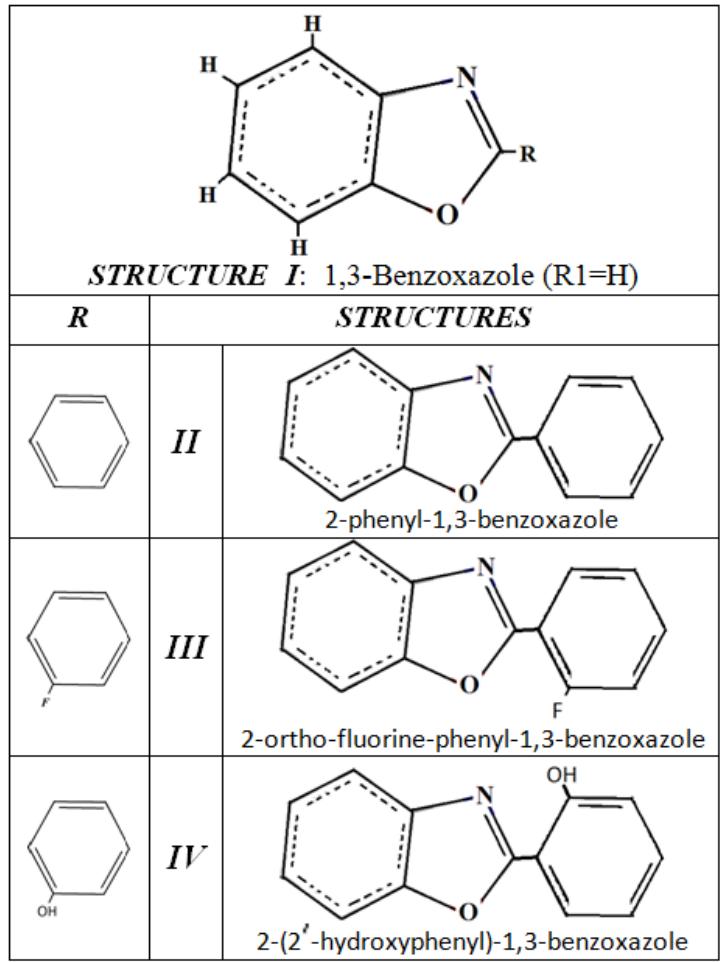


around N. The planarity configuration observed in parent structure is preserved in benzoxazole substituted; see the dihedral angle of 180 degrees in Fig. 2 and Table II. On the other hand, one can see that the phenyl ring (structure II) has little effect on nitrogen and oxygen atoms. Specifically, the negative charge in nitrogen atom is decreasing, while the negative charges on the oxygen atom and carbon atoms near them are increasing (see Table III). The fluorine atom (structure III) substituted in the ortho-position causes the decrease of the negative charge on the nitrogen atom, only that in greater proportion that for the previous case, it is attributed to the electron-attracting effect of fluorine atom; while the hydroxyl group (structure IV) has a higher effect on the nitrogen and oxygen atoms increasing the negative charge of them.

\section{3.b. Absorption and emission spectra}

The absorption and emission spectra of parent and IV structures were obtained from literature $[13,14]$. In order to validate the method employed to predict the absorption and emission spectra of compounds more accurately, the experimental data were compared with the calculated data by TD-B3LYP/6-31+G(d) methods. The comparisons of results in gas phase and liquid phase for each structure were listed in Table IV and the peaks with the largest wavelength $\left(\lambda_{\max }\right)$ were selected to be compared, also it is done a comparison of the oscillator strength and stokes shift. The superposition of the absorption and emission spectra obtained in the gas phase of the parent structure is shown in Fig. 4 , and the orbitals given rise to the excited states are shown schematically.

The first thing to be highlighted is that, in the parent structure, the lowest 4 singlet excited states are between 199.13 and $245.33 \mathrm{~nm}$. The lowest singlet is not the one with the largest transition probability, but the second, both states involve the HOMO and sub-HOMO occupied and the LUMO and super-LUMO empty orbitals (see Fig. 3).

The first and second excited states are $\pi \rightarrow \pi^{*}$ transitions which differ in the dominant configuration. For the first excited state it is $30 \rightarrow 32$, building up density between the $\mathrm{C}-\mathrm{N}$ and $\mathrm{C}-\mathrm{O}$ bonds and depleting the $\mathrm{C}-\mathrm{C}, \mathrm{N}=\mathrm{C}$ and $\mathrm{O}-\mathrm{C}$ bonds. For the second excited state it is $31 \rightarrow 32$,
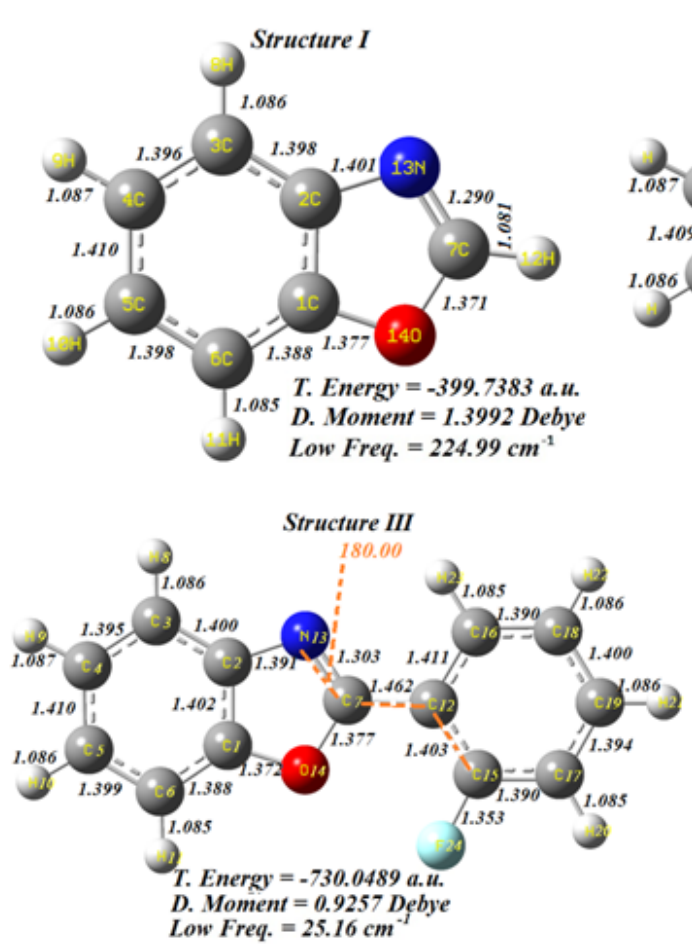
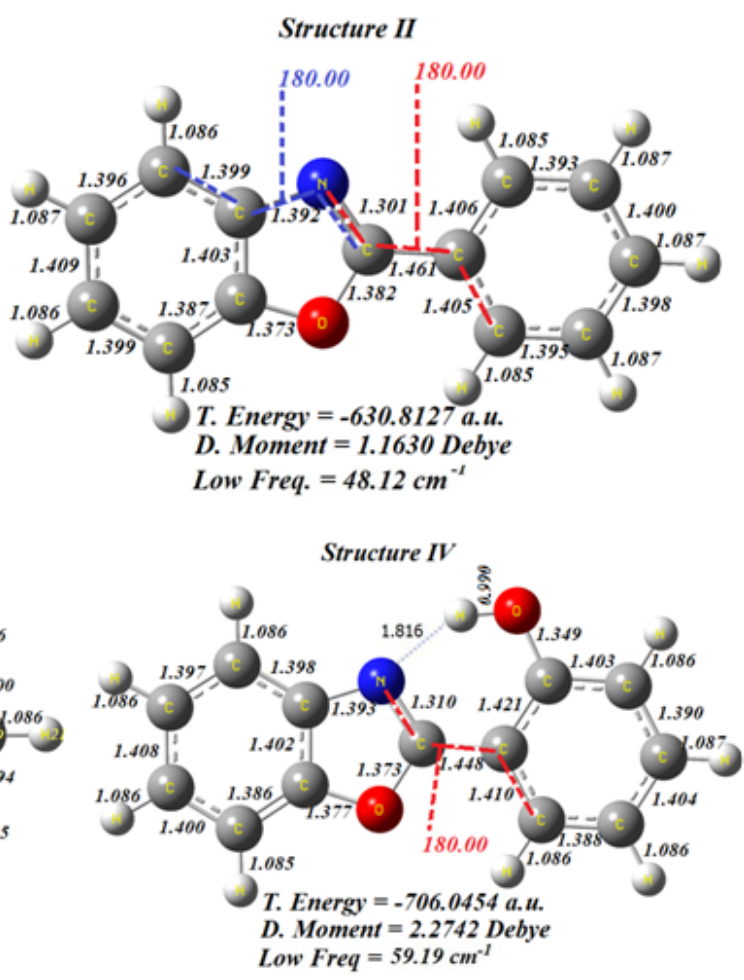

Fig. 2. Geometric structure of the ground state in the gas phase in each molecule studied 
Table II

Geometrical parameters of the ground state each structure in gas phase and liquid phase at the B3LYP/6-31+G(d) level. Distances in $\AA$ Á, angles in degree and dipole moment in Debye.

\begin{tabular}{|c|c|c|c|c|c|c|c|c|c|c|c|c|}
\hline \multirow[t]{3}{*}{ Parameter } & \multicolumn{12}{|c|}{ Molecular Structures } \\
\hline & \multicolumn{3}{|c|}{$\mathbf{I}$} & \multicolumn{3}{|c|}{ II } & \multicolumn{3}{|c|}{ III } & \multicolumn{3}{|c|}{ IV } \\
\hline & GAS & TOL & ЕTH & GAS & TOL & ЕTH & GAS & TOL & ЕTH & GAS & TOL & ЕTH \\
\hline $\mathrm{Cl}-\mathrm{C} 2$ & 1.4014 & 1.4012 & 1.4010 & 1.4029 & 1.4027 & 1.4025 & 1.4024 & 1.4021 & 1.4017 & 1.4016 & 1.4015 & 1.4015 \\
\hline C6-Cl & 1.3880 & 1.3882 & 1.3883 & 1.3870 & 1.3871 & 1.3873 & 1.3875 & 1.3876 & 1.3877 & 1.3859 & 1.3860 & 1.3862 \\
\hline $\mathrm{C} 2-\mathrm{N} 13$ & 1.4008 & 1.4018 & 1.4028 & 1.3921 & 1.3931 & 1.3942 & 1.3906 & 1.3915 & 1.3926 & 1.3933 & 1.3938 & 1.3946 \\
\hline C7-N13 & 1.2902 & 1.2911 & 1.2925 & 1.3011 & 1.3020 & 1.3033 & 1.3031 & 1.3037 & 1.3045 & 1.3101 & 1.3104 & 1.3106 \\
\hline $\mathrm{C} 7-\mathrm{Cl2}$ & & & & 1.4607 & 1.4606 & 1.4608 & 1.4617 & 1.4618 & 1.4617 & 1.4479 & 1.4485 & 1.4493 \\
\hline $\mathrm{Cl2}-\mathrm{Cl} 16$ & & & & 1.4062 & 1.4067 & 1.4074 & 1.4109 & 1.4112 & 1.4116 & 1.4209 & 1.4207 & 1.4202 \\
\hline $\mathrm{Cl2}-\mathrm{Cl5}$ & & & & 1.4051 & 1.4056 & 1.4062 & 1.4028 & 1.4028 & 1.4029 & 1.4103 & 1.4102 & 1.4102 \\
\hline $\mathrm{C} 16-23$ & & & & 1.0854 & 1.0852 & 1.0852 & 1.0849 & 1.0847 & 1.0846 & 1.3492 & 1.3517 & 1.3554 \\
\hline C15-24 & & & & 1.0852 & 1.0851 & 1.0851 & 1.3535 & 1.3561 & 1.3588 & 1.0855 & 1.0855 & 1.0854 \\
\hline $\mathrm{Cl}-\mathrm{C} 2-\mathrm{C} 3$ & 119.99 & 120.01 & 120.04 & 119.87 & 119.88 & 119.91 & 119.90 & 119.91 & 119.92 & 120.01 & 120.03 & 120.06 \\
\hline $\mathrm{N} 13-\mathrm{C} 7-\mathrm{Cl} 2-\mathrm{Cl} 5$ & & & & 180.00 & 180.00 & 180.00 & 180.00 & 180.00 & 180.00 & 180.00 & 180.00 & 180.00 \\
\hline D.MOMENT & 1.3992 & 1.6277 & 1.9238 & 1.1630 & 1.4080 & 1.7690 & 0.9257 & 1.0978 & 1.2904 & 2.2742 & 2.6665 & 3.1474 \\
\hline
\end{tabular}

Table III

Mulliken charges (e) each structure of the ground state in gas phase and liquid phase obtained by B3LYP/6-31+G(d) method.

\begin{tabular}{|c|c|c|c|c|c|c|c|c|c|c|c|c|}
\hline \multirow[t]{3}{*}{ Atom } & \multicolumn{12}{|c|}{ Molecular Structures } \\
\hline & \multicolumn{3}{|c|}{$\mathbf{I}$} & \multicolumn{3}{|c|}{ П } & \multicolumn{3}{|c|}{ Ш } & \multicolumn{3}{|c|}{ IV } \\
\hline & GAS & TOL & ЕTH & GAS & TOL & ETH & GAS & TOL & ETH & GAS & TOL & ЕTH \\
\hline C1 & 0.599 & 0.618 & 0.638 & 0.644 & 0.645 & 0.644 & 0.710 & 0.714 & 0.718 & 0.817 & 0.817 & 0.814 \\
\hline $\mathrm{C} 2$ & 0.891 & 0.925 & 0.963 & 0.434 & 0.448 & 0.462 & 0.497 & 0.515 & 0.534 & 0.390 & 0.398 & 0.406 \\
\hline $\mathrm{C3}$ & -0.750 & -0.785 & -0.825 & -0.661 & -0.679 & -0.695 & -0.714 & -0.730 & -0.744 & -0.526 & -0.531 & -0.535 \\
\hline C6 & -0.802 & -0.816 & -0.827 & -0.723 & -0.721 & -0.714 & -0.729 & -0.730 & -0.728 & -0.973 & -0.973 & -0.968 \\
\hline C7 & 0.325 & 0.337 & 0.350 & 0.574 & 0.591 & 0.615 & 0.823 & 0.832 & 0.843 & 0.933 & 0.940 & 0.948 \\
\hline N13 & -0.342 & -0.375 & -0.414 & -0.307 & -0.338 & -0.377 & -0.290 & -0.317 & -0.351 & -0.443 & -0.452 & -0.463 \\
\hline 014 & -0.327 & -0.331 & -0.332 & -0.388 & -0.390 & -0.390 & -0.380 & -0.385 & -0.391 & -0.389 & -0.391 & -0.391 \\
\hline $\mathrm{C} 12$ & & & & 0.436 & 0.432 & 0.615 & 0.399 & 0.414 & 0.432 & 0.839 & 0.841 & 0.844 \\
\hline C15 & & & & -0.332 & -0.329 & -0.321 & 0.222 & 0.215 & 0.209 & -0.902 & -0.897 & -0.885 \\
\hline C16 & & & & -0.381 & -0.366 & -0.340 & -0.968 & -0.953 & -0.927 & -0.396 & -0.376 & -0.352 \\
\hline C17 & & & & -0.390 & -0.410 & -0.437 & -0.186 & -0.195 & -0.204 & -0.197 & -0.220 & -0.252 \\
\hline H8 & 0.202 & 0.209 & 0.215 & 0.197 & 0.204 & 0.211 & 0.197 & 0.204 & 0.212 & 0.197 & 0.205 & 0.213 \\
\hline H11 & 0.201 & 0.211 & 0.222 & 0.197 & 0.207 & 0.219 & 0.201 & 0.210 & 0.220 & 0.202 & 0.212 & 0.223 \\
\hline 23 & & & & 0.217 & 0.218 & 0.219 & 0.229 & 0.231 & 0.231 & -0.651 & -0.669 & -0.690 \\
\hline 24 & & & & 0.208 & 0.213 & 0.221 & -0.335 & -0.343 & -0.352 & 0.210 & 0.216 & 0.224 \\
\hline
\end{tabular}

Table IV

Absorption and emission spectra, and Stokes shifts (in $\mathrm{nm}$ ) for each structure, in gas phase, toluene and ethanol. Oscillator strengths are also shown.

\begin{tabular}{|c|c|c|c|c|c|c|}
\hline \multirow{3}{*}{$\begin{array}{l}\text { Condition } \\
\text { GAS }\end{array}$} & \multicolumn{2}{|c|}{ Parameter } & \multicolumn{4}{|c|}{ Molecular Structure } \\
\hline & \multirow[b]{2}{*}{ Absorption } & \multirow{3}{*}{$\begin{array}{l}\text { Wavelength } \\
\text { Osc. Strength }\end{array}$} & I & II & III & IV \\
\hline & & & 245.35 & 295.32 & 299.42 & 317.68 \\
\hline & \multirow{3}{*}{ Emission } & & 0.0454 & 0.7399 & 0.7003 & 0.3991 \\
\hline & & Wavelength & 314.47 & 355.26 & 389.51 & 391.94 \\
\hline & & Osc. Strength & 0.0528 & 0.7262 & 0.5710 & 0.4802 \\
\hline & \multicolumn{2}{|c|}{ Stokes Shift } & 69.12 & 59.94 & 90.09 & 74.26 \\
\hline \multirow[t]{5}{*}{ TOLUENE } & \multirow[t]{2}{*}{ Absorption } & Wavelength & 246.34 & 304.24 & 308.01 & 317.92 \\
\hline & & Osc. Strength & 0.0844 & 0.9201 & 0.8962 & 0.6828 \\
\hline & \multirow[t]{2}{*}{ Emission } & Wavelength & 330.10 & 376.19 & 420.05 & 407.16 \\
\hline & & Osc. Strength & 0.0888 & 0.9004 & 0.7114 & 0.6368 \\
\hline & \multicolumn{2}{|c|}{ Stokes Shift } & 83.76 & 71.95 & 112.04 & 89.24 \\
\hline \multirow[t]{5}{*}{ ETHANOL } & \multirow[t]{2}{*}{ Absorption } & Wavelength & 247.97 & 302.01 & 317.19 & 328.88 \\
\hline & & Osc. Strength & 0.1680 & 0.8707 & 1.0906 & 0.8426 \\
\hline & \multirow[t]{2}{*}{ Emission } & Wavelength & 335.72 & 399.71 & 436.24 & 432.73 \\
\hline & & Osc. Strength & 0.1666 & 1.0728 & 0.9072 & 0.8236 \\
\hline & \multicolumn{2}{|c|}{ Stokes Shift } & 87.75 & 97.70 & 119.05 & 103.85 \\
\hline
\end{tabular}



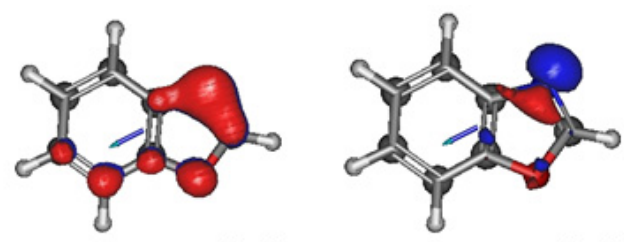

I, HOMO-3, $\pi$ (28)
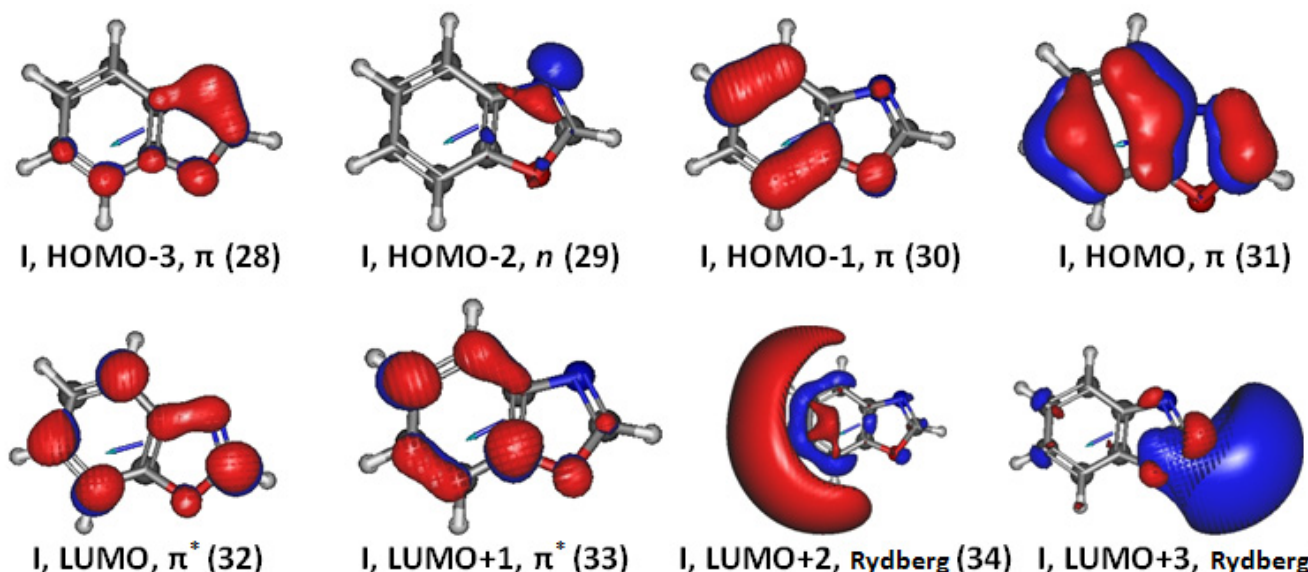

I, LUMO+1, $\pi^{*}(33)$

I, LUMO+2, Rydberg (34) I, LUMO+3, Rydberg (35)

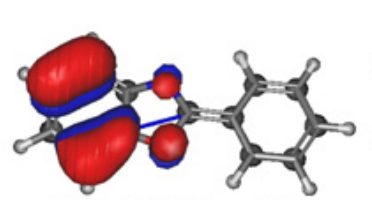

II, HOMO-1, $\pi$ (50)
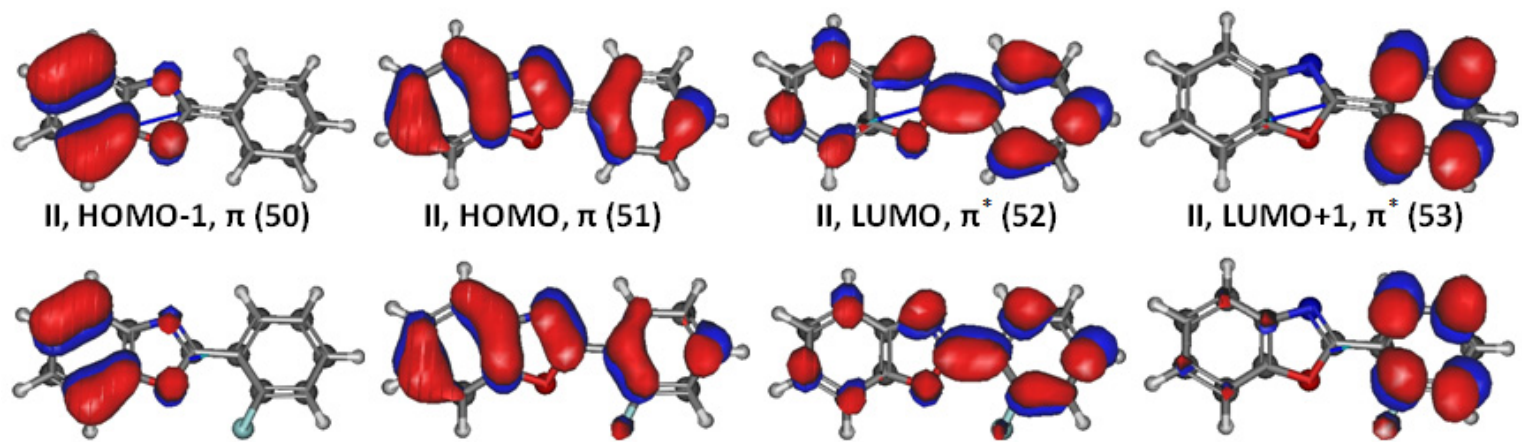

III, HOMO-1, $\pi$ (54)

III, HOMO, $\pi(55)$

III, LUMO, $\pi^{*}(56)$

III, LUMO+1, $\pi^{*}(57)$

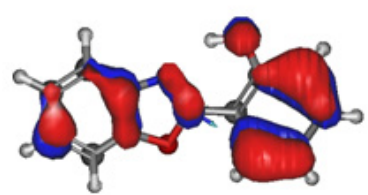

IV, HOMO-1, $\pi$ (54)

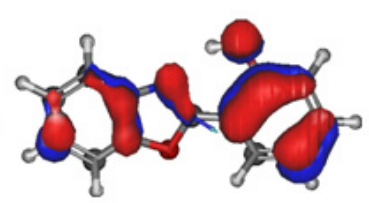

IV, HOMO, $\pi(55)$

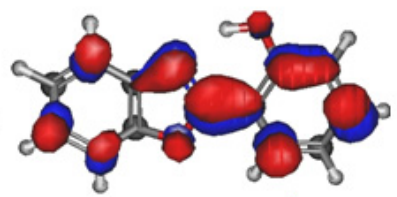

IV, LUMO, $\pi^{*}(56)$

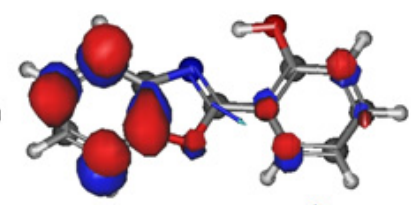

IV, LUMO+1, $\pi^{*}$ (57)

Fig. 3. The plots of the frontier molecular orbital of compounds I, II, III and IV obtained by TD-B3LYP/6-31+G(d) method.

with exactly the same effect. Therefore, one can expect (as observed, Fig. 3) an evolution toward a $\mathrm{C}=\mathrm{N}-\mathrm{C}$ structure, strengthening of the $\mathrm{C}-\mathrm{O}$ bond and weakening of the $\mathrm{O}-\mathrm{C}$ bond. The third excited state is an $n \rightarrow \pi^{*}$ transition $(29 \rightarrow 32)$ which, therefore, has a lower transition probability.

Using the optimum geometries of the excited state, calculated in gas phase and the toluene and ethanol solvents, it is possible to calculate the fluorescence spectra of each structure studied; a straightforward geometry optimization of the first excited state of the parent structure in the gas phase does not necessarily lead to the optimum geometry of the excited state. A planar transition state is obtained instead, which is shown in Fig. 1 together with the true minimum (as shown by the positive lowest eigenvalue of the Hessian). The structures of the true minimum exhibit a rupture of the $\mathrm{O}-\mathrm{C} 7$ bond, and their main characteristic is that the oxazole ring is not anymore planar, especially the $\mathrm{C}-\mathrm{H}$ group between $\mathrm{N}$ and $\mathrm{O}$. The second main characteristic is the evolution of the single C-N and $\mathrm{N}-\mathrm{C}$ bonds in the oxazole moiety toward double bonds; the $\mathrm{C}-\mathrm{N}=\mathrm{C}$ group evolved toward $\mathrm{C}=\mathrm{N}-\mathrm{C}$, the $\mathrm{C}-\mathrm{O}-\mathrm{C}$ toward $\mathrm{C}=\mathrm{O}-\mathrm{C}$ and the terminal $\mathrm{CH}$ group has now two lone pairs on carbon. The main emission line is located at $314.47 \mathrm{~nm}$, with a Stokes shift of $69.12 \mathrm{~nm}$ and oscillator strength of 0.0528 (see Table IV), more in line with experimental data.

The data in Table IV also show the solvatochromic effect reflected in the calculations is extremely noticeable, in 
agreement with the reported experimentally [14]. A bathochromic shift of $21.25 \mathrm{~nm}$ for parent structure and $40.79 \mathrm{~nm}$ for the IV structure is calculated in going from gas phase to ethanol, while a shorter $15.22 \mathrm{~nm}$ shift is observed in the IV structure in going from gas to toluene. The absorption wavelength determined in ethanol at the TD-B3LYP/6-31+G(d) level by us, $328.88 \mathrm{~nm}$, is in almost perfect agreement with the value reported experimentally, $327 \mathrm{~nm}$, while the fluorescence wavelength, calculated at $432.73 \mathrm{~nm}$ is also in relative agreement with the experimental $468 \mathrm{~nm}$ value.

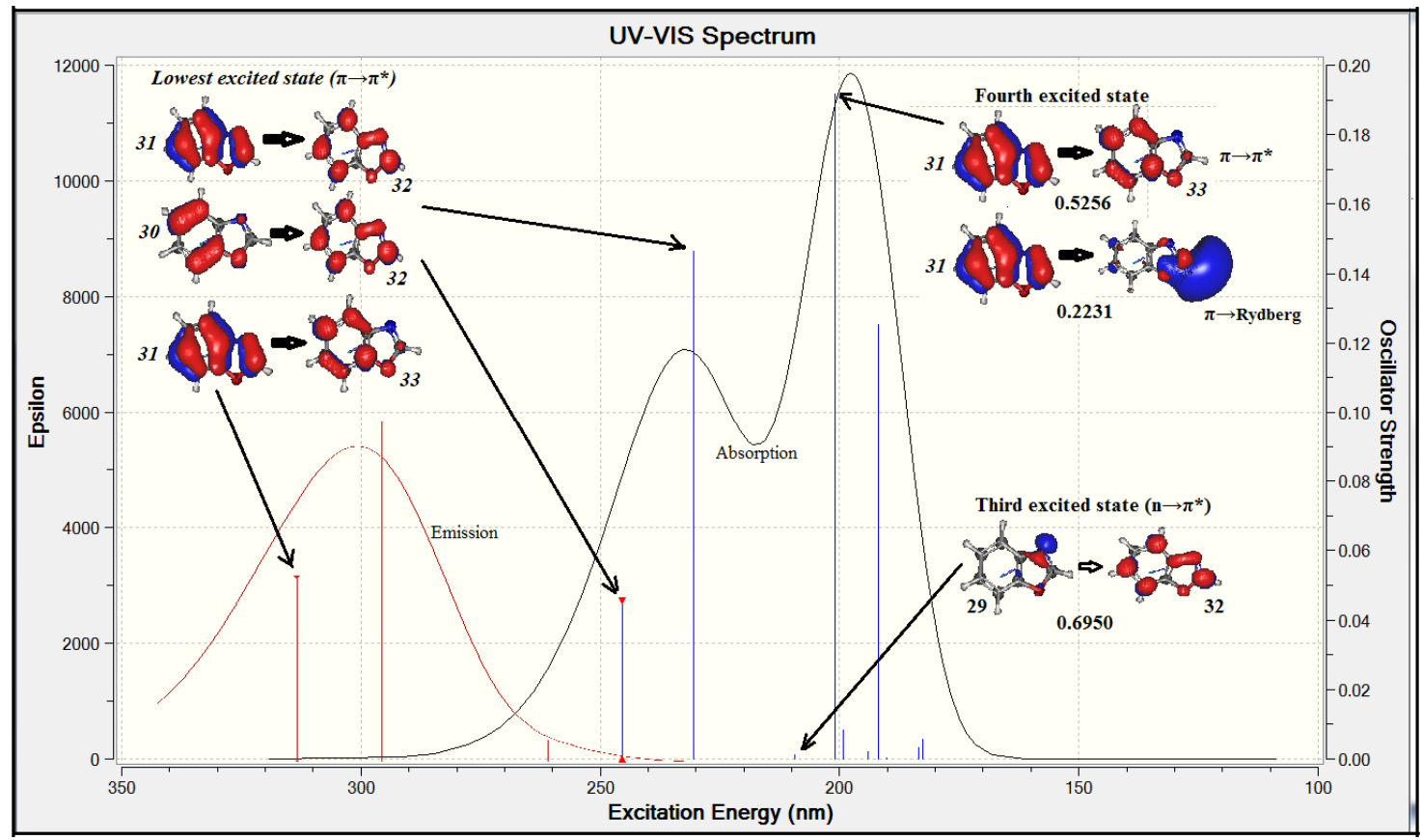

Fig. 4. Superposition of the absorption and emission spectra of I structure in gas phase, calculated at the TD-B3LYP/6-31+G(d) level.

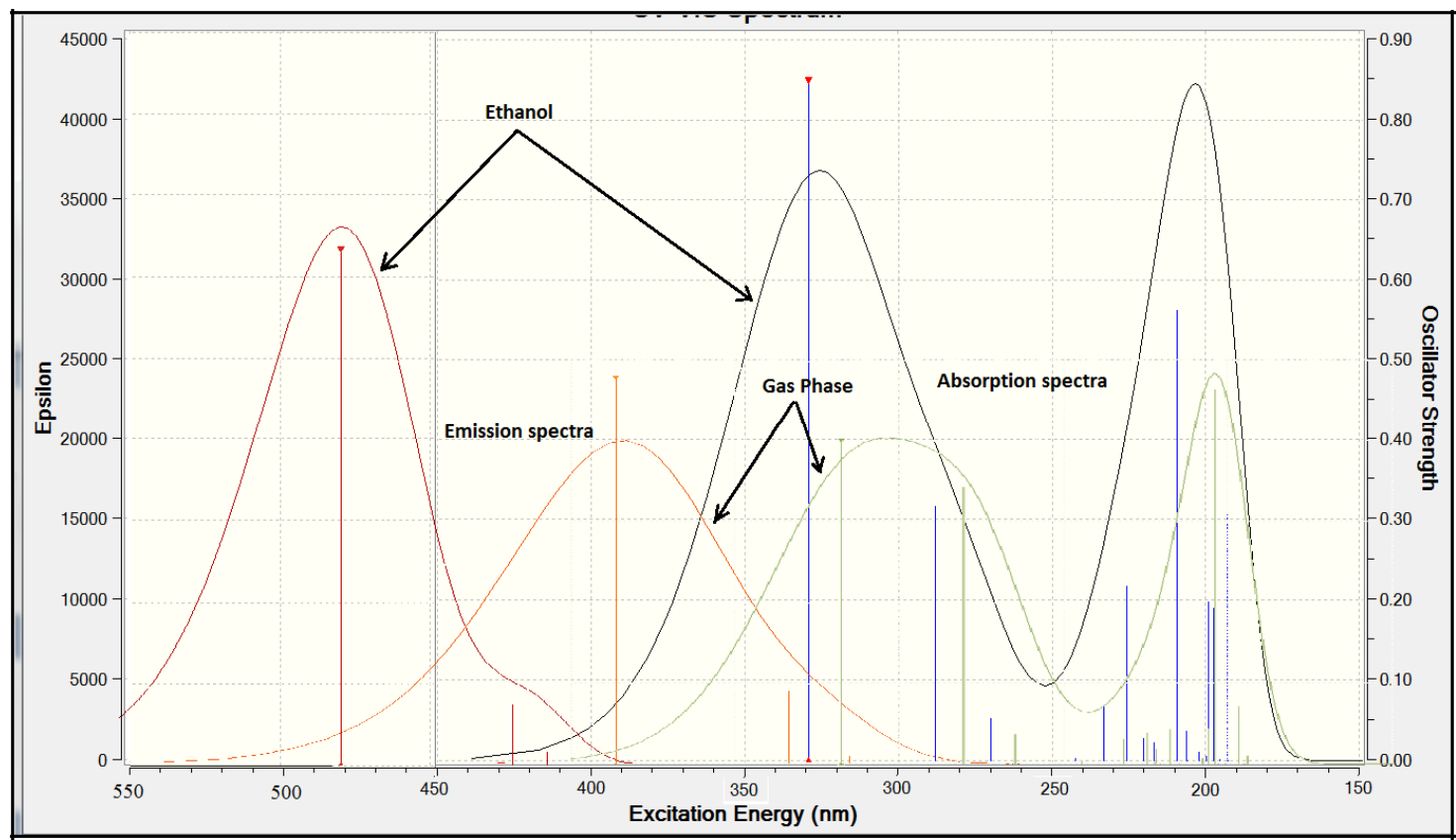

Fig. 5. Superposition of the absorption and emission spectra in gas phase and ethanol for the IV structure. 
Table V

Mulliken charges (e) each structure of the first excited state in gas and ethanol, obtained by TD-B3LYP/6-31+G(d) method.

\begin{tabular}{|c|c|c|c|c|c|c|c|c|}
\hline \multirow[t]{3}{*}{ ATOM } & \multicolumn{8}{|c|}{ Molecular Structures } \\
\hline & \multicolumn{2}{|c|}{$\mathbf{I}$} & \multicolumn{2}{|c|}{ Ш } & \multicolumn{2}{|c|}{ III } & \multicolumn{2}{|c|}{ IV } \\
\hline & GAS & ETH & GAS & ЕTH & GAS & ETH & GAS & ETH \\
\hline $\mathrm{Cl}$ & 0.428 & 0.655 & 0.505 & 0.527 & 0.446 & 0.452 & 0.373 & 0.418 \\
\hline $\mathrm{C} 2$ & 1.036 & 1.002 & 0.454 & 0.466 & 0.576 & 0.630 & 0.539 & 0.557 \\
\hline $\mathrm{C} 3$ & -0.743 & -0.964 & -0.630 & -0.664 & -0.682 & -0.716 & -0.568 & -0.602 \\
\hline $\mathrm{C} 6$ & -0.699 & -0.633 & -0.631 & -0.627 & -0.641 & -0.637 & -0.654 & -0.653 \\
\hline $\mathrm{C} 7$ & -0.008 & -0.011 & 0.547 & 0.584 & 0.789 & 0.798 & 0.825 & 0.819 \\
\hline N13 & -0.348 & -0.417 & -0.287 & -0.355 & -0.269 & -0.348 & -0.411 & -0.443 \\
\hline 014 & -0.302 & -0.318 & -0.341 & -0.357 & -0.321 & -0.351 & -0.350 & -0.364 \\
\hline $\mathrm{Cl2}$ & & & 0.529 & 0.584 & 0.446 & 0.491 & 0.906 & 0.923 \\
\hline $\mathrm{Cl5}$ & & & -0.349 & -0.360 & 0.189 & 0.153 & -0.890 & -0.878 \\
\hline $\mathrm{Cl} 6$ & & & -0.452 & -0.420 & -0.948 & -0.925 & -0.500 & -0.457 \\
\hline $\mathrm{Cl} 7$ & & & -0.357 & -384 & -0.156 & -0.168 & -0.113 & -0.162 \\
\hline H8 & 0.220 & 0.233 & 0.207 & 0.221 & 0.210 & 0.223 & 0.201 & 0.220 \\
\hline Hll & 0.232 & 0.241 & 0.209 & 0.230 & 0.213 & 0.231 & 0.204 & 0.227 \\
\hline 23 & & & 0.214 & 0.216 & 0.225 & 0.228 & -0.559 & -0.615 \\
\hline 24 & & & 0.201 & 0.215 & -0.329 & -0.344 & 0.213 & 0.220 \\
\hline
\end{tabular}

The superposition of the absorption and emission spectra obtained in the gas phase and ethanol for the IV structure are shown in Fig. 5 (The same for toluene is not shown since it is intermediate between the cases mentioned); it is clear that the absorption and fluorescence bands suffers a large bathochromic effect when the solvent is included and when the polarity of the solvent increases. With the I, II and III structures is obtained approximately the same results, especially when they are solvated (See Table IV).

\section{3.c. Geometry and charge of the first excited state (S1)}

The geometries of the first excited state (S1) were optimized at the TD-B3LYP/6-31+G(d) level of theory. The optimized geometrical parameters for each structure studied (the transition state together with the true minimum) are shown in Fig. 6 and the serial numbers of atoms is indicated in I and III structures from the Fig. 2. The transition states in each structure exhibit an almost completely planar configuration, but the true minimum of the parent structure exhibit a rupture of the 014-C7 bond, with torsion angles C3-C2-N13-C7 and C2-N13-C7-H12 of -171.67 and -147.44, respectively, therefore increasing noticeably the distance between those both atoms. While, for the derivative structures the bond lengths 014C7 are all larger than those of the ground states but are not broken. As shown in Fig. 6, the bond lengths C2-N13 are shorter than those of the ground state and the bond lengths N13-C7 are all longer than those of the ground state. The lowest singlet transitions for the four benzoxazoles are the transition from the HOMO to LUMO, so the change of bond length can be understood by analyzing the HOMO and LUMO orbitals. There is a smaller density on the $\mathrm{C} 2-\mathrm{N} 1$ bond for the HOMO, but the electron density for the LUMO increases, so the bond length of C2-N13 decreases. The longer bonds N13-C7 can also be interpreted in terms of the patterns of HOMO and LUMO.

The Table $\mathrm{V}$ shown the Mulliken charges in each atom of each structure in gas phase and ethanol solvent (the toluene gives values intermediate). As one can see in Table $\mathrm{V}$, the oxazole ring decreases its charge upon excitation, giving electrons to the other fragments. The phenyl substituent is obviously able to remove more electrons than the hydrogen atom, the charge transfer excited state is more stable and less energy is required for the transition. The halogen substituent in the orthoposition (fluorine) decreases the negative charge on oxygen and nitrogen atoms, while the hydroxyl group to increase the negative charge on them. We saw that the inclusion of the solvent worked in the same sense, increasing the negative charges on the Oxygen and Nitrogen atoms, stabilizing a more closed excited state structure. It is not surprising then that the emission in the liquid phase occurs at longer wavelengths than in the gas phase. The effect of the solvent is more noticeable in the Stokes shift which increases in all structures upon addition of the solvent. 

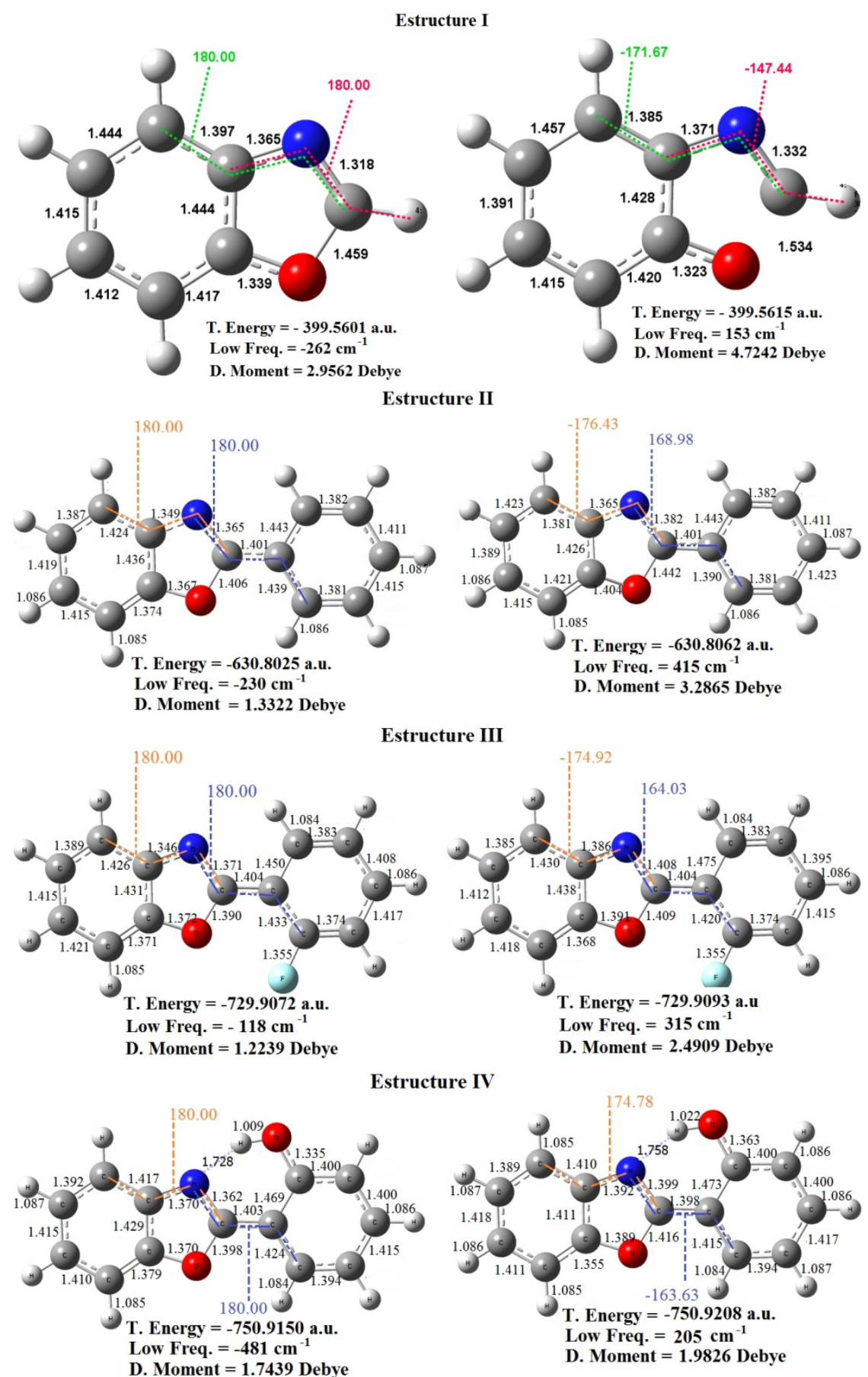

Fig. 6. Geometric structure of the first excited state in the gas phase from each molecule studied.

\section{Results and discussion}

We have performed DFT and TD-DFT calculations of the structure of the $\mathrm{S}_{0}$ and $\mathrm{S}_{1}$ states of several benzoxazoles, including the parent structure. Geometrical structures, molecular orbitals, absorption and emission spectra of these benzoxazole compounds have been discussed; we have found that substitution of the benzoxazoles skeleton affects both the absorption and emission spectrum, mainly through the modification of the structure of the excited states. In general, one can conclude that:

- The reach from the study of the parent structure is that the important excited state 
implies a breaking of the oxazole ring. The largest effect is observed in liquid phase and it is increased with the polarity of the solvent. The substituent effect implies the no breaking the oxazole ring, helping to stabilize the structure in the excited state, but conserving the non-planarity of the oxazole ring reducing the delocalization electronic on the benzene ring. All in all, we can say that the phenyl substituent in 2 shifts both the absorption and emission transitions of the 1,3-benzoxazole toward the red. The halogen substituent in the ortho-position of the phenyl substituent increases this red shift.

- The substitutions of phenyl and hydroxyl group and fluorine atoms reduce the energy gaps between HOMO and LUMO orbitals and make the transition from HOMO to LUMO easier. The calculated results of absorption and emission properties shows III and IV can act as good electron-transfer materials, which can increase your properties of emission laser.

- The agreement may be reasonably good, error of about 20-30 nm for the absorption wavelength, and about 3-5 $\mathrm{nm}$ for the emission wavelength in parent structure. While, is obtained an error of about $2 \mathrm{~nm}$ for the absorption wavelength and about $35 \mathrm{~nm}$ for the emission wavelength in IV structure.

- Further research is needed on the effect of meta and para halogen substitution, as well as on the effect of multiple substitution.

\section{Acknowledgements}

The authors express our gratitude to the Universidad Popular del Cesar for their financial support and where this work was carried out. 